The Journal of Development and Administrative Studies, Vol. 22, No. 1-2, pp. 15-26, 2014

(c) CEDA/TU, 2000, US Library of Congress, Catlog Card No.: 79-915209, ISSN: 2091-0339

\title{
International Trade Effects: Lower Cost or Higher Quality?
}

- Le Duc Niem*

\begin{abstract}
In this paper, we modify the model of Liao (2008) to investigate the trade of quality differentiated goods between countries. We show that main effects of the trade are on quality improvement of all goods and the trade does not make the goods cheaper. Thus, we argue that New Trade Theory might not explain international trade that is based on quality differentiation.
\end{abstract}

Keywords: Vertical intra-industry trade, new trade theory and product quality

JEL classification numbers: F12 and F15.

\section{Introduction}

New Trade Theory (NTT) suggests that international patterns of trade depend in large part on economies of scale and good variety. For example, Krugman (1979) and Lancaster (1980) promote an explanatory framework that associated international trade with economies of scale in production and varieties of horizontally differentiated products. They suggest that international trade will offer consumers cheaper and more choices of goods. However, goods in these models are assumed to be identical in quality so NTT is more suited to explain horizontal intra-industry trade (HIIT) rather than vertical intra-industry trade (VIIT). HIIT is the bilateral trade of different products of the same quality, whereas VIIT is the bilateral trade of quality differentiated products within the same industry.

Most empirical studies do not make a distinction between HIIT and VIIT, each of which may have different causes. Greenaway et al. (1994) and more recently Fontagné et al. (2006) construct a method of disentangling the total share of IIT into horizontal and vertical components. They show that the majority of IIT is, in fact, VIIT. In addition, VIIT accounts for a large proportion of international trade, and the world's increase in IIT is due principally to increase in the two-way trade of vertically differentiated products. In spite of its prevalence, and in contrast with horizontal IIT, the exact effects of VIIT on firms' choices have yet to be clearly explained (Fontagné et al., 2006). Niem and Kim (2014) employ the model of

\footnotetext{
Dr. Niem is Dean of faculty of Economics, Tay Nguyen University, 567 Le Duan Street, Buon
} Ma Thuot, Republic of Vietnam. Email:lemiem@gmail.com 
Wauthy (1996) to examine effects of VIIT, but only in the short-run with only two firms and fixed quality levels of their goods. This model shows that VIIT effects are mainly on the cost reduction of goods. However, William et al. (1967) find a strong linkage between the intensity of R\&D effort and the international activities in industries of the US. Aw et al. (2008) review empirical studies on R\&D investments of firms that produce goods for international trade. They find that the firms tend to invest in $R \& D$ activities. Actually, $R \& D$ investment (in product innovation) generally results in an increase in the quality levels of goods however it may result in a higher average cost due to an additional fixed cost in production.

Thus, when countries trade with each other and when firms are allowed to adjust their good quality, what do the firms optimally choose to build in their goods - $a$ higher quality or a lower cost?

To answer this question, we construct a model that is progressively developed by Gabszewicz and Thisse (1979), Shaked and Sutton (1982), and Tirole (1988). In particular, we employ the findings of the most recent related model (Liao, 2008). In setting up our model, we follow through on Liao's (2008) finding that the market is covered with a corner solution of only two firms at equilibrium. In this trade scenario, firms are allowed to choose their product qualities. As a result, we can investigate the impact of VIIT on average costs, variety, and quality of goods. We find that VIIT does not provide consumers with more choices, and makes goods even more costly as a consequence of quality improvement of goods. Thus, we argue that NTT might not explain trade of quality differentiated goods.

\section{The Model Settings}

We assume that a region consists of only two similar countries: Home and Foreign and a single industry with identical goods, but of differing quality ${ }^{1}$. The goods are purchased by a number of consumers: $T$, in Home and $U$, in Foreign $(T, U>0)$. It is reasonable to assume that $\mathrm{T}$ and $\mathrm{U}$ are proxies for Home and Foreign sizes, respectively.

In each countries, the population of consumers is uniformly distributed between $\underline{\theta}$ and $\bar{\theta}$. When the degree of consumers' heterogeneity is high, it is conceivable many firms may coexist at equilibrium. However, Liao (2008) points out that we can keep our model simple by limiting the consumers' heterogeneity. Thus, we assume $\bar{\theta} / \underline{\theta} \in(2,4.7125)$ as then the market will be covered with a corner solution by only two firms.

\footnotetext{
Many empirical works have found that VIIT is concentrated in developed countries with similar levels of income and technology. That is the reason we model the game with two similar countries.
} 
Each consumer may purchase at most one good from the industry. A consumer's preference is described as follows:

$$
U_{j}=\left\{\begin{array}{cc}
\theta s_{i}-p_{i} & \text { if buying the good } \\
0 & \text { if not buying }
\end{array}\right.
$$

where $s_{i}$ is quality units of the good and $p_{i}$ is the price paid by the consumer. Basically, this function is an indirect utility function of a consumer identified by a parameter $\theta$ as in Sutton (1986), Wauthy (1996), Beloqui and Usategui (2005), and Liao (2008). The consumer will decide to buy the good which gives him the highest and non-negative utility.

In each countries, there is a large number of free-entry/exit firms which are willing to produce one type of the good. We use the quality cost function presented in Mussa and Rosen (1978), Liao (2008), and Motta (1993): $f\left(s_{i}\right)=\frac{1}{2} s_{i}^{2}$ for all firms. $^{2}$ As assumed in previous papers, the production cost is zero for all firms. Thus, total cost incurred by firmi is:

$$
T C_{i}=f\left(s_{i}\right)=\frac{1}{2} s_{i}^{2}
$$

We model a game consisting of two stages as in Liao (2008). In the first stage, all firms simultaneously select quality levels for their products. In the second stage, they compete in price.

We first summarize Liao's (2008) model in section 2, and present the scenario of the Unitary Country. Then we extend it to a general situation with an arbitrary market size in section 3. Finally, in section 4, to identify the effects of trade on a firm's behavior, we consider the game in each country separately, as an autarkic case. We then consider the game when two countries trade with each other. In this case, we assume there are no trade barriers between Home and Foreign, and that transportation cost is zero.

\section{Conceptual Analysis of the Model}

\subsection{The unitary country (Liao,2008)}

Liao (2008) considers a model as presented in section 1 but with a market size of 1 . As the market size is 1, we call the market in Liao (2008) the Unitary Country.

2 Mussa and Rosen (1978), Liao (2008), and Motta (1993) use this quadratic form of quality cost function. 
Liao (2008) finds the optimal prices and qualities of two firms in two sequent stages: quality choice and price competition. To simplify our model, we let $\bar{\theta}=b$ and $\underline{\theta}=1$ and have, in the second stage, three market configurations (regions) as well as profit maximization problems faced by two firms in each region as follows (see pages 31-34 of Liao, 2008): ${ }^{3}$

\section{Case I: An uncovered market}

$$
\left\{\begin{array}{l}
\text { Firm 1: } \max _{s_{1}} \pi_{1}^{* *}=\max _{s_{1}}\left\{\frac{4 b^{2} s_{1}^{2}\left(s_{1}-s_{2}\right)}{(b-1)\left(4 s_{1}-s_{2}\right)^{2}}-\frac{1}{2} s_{1}^{2}\right\} \\
\text { Firm 2: } \max _{s_{2}} \pi_{2}^{* *}=\max _{s_{2}}\left\{\frac{b^{2} s_{1} s_{2}\left(s_{1}-s_{2}\right)}{(b-1)\left(4 s_{1}-s_{2}\right)^{2}}-\frac{1}{2} s_{2}^{2}\right\}
\end{array}\right.
$$

\section{Case II: A covered market with a corner solution}

$$
\left\{\begin{array}{l}
\text { Firm 1: } \max _{s_{1}} \pi_{1}^{c}=\max _{s_{1}}\left\{\frac{\left[b s_{1}-(b-1) s_{2}\right]^{2}}{4(b-1)\left(s_{1}-s_{2}\right)}-\frac{1}{2} s_{1}^{2}\right\} \\
\text { Firm 2: } \max _{s_{2}} \pi_{2}^{c}=\max _{s_{2}}\left\{\frac{s_{2}\left[(b-2) s_{1}-(b-1) s_{2}\right]}{2(b-1)\left(s_{1}-s_{2}\right)}-\frac{1}{2} s_{2}^{2}\right\}
\end{array}\right.
$$

In addition, the optimal prices are obtained from:

$$
\left\{\begin{array}{c}
p_{1}^{c}=\left[s_{2}+b\left(s_{1}-s_{2}\right)\right] / 2 \\
p_{2}^{c}=s_{2}
\end{array}\right.
$$

\section{Case III: A covered market with an interior solution}

$$
\left\{\begin{array}{l}
\text { Firm 1: } \max _{s_{1}} \pi_{1}^{*}=\max _{s_{1}}\left\{\frac{(2 b-1)^{2}\left(s_{1}-s_{2}\right)}{9(b-1)}-\frac{1}{2} s_{1}^{2}\right\} \\
\text { Firm 2: } \max _{s_{2}} \pi_{2}^{*}=\max _{s_{2}}\left\{\frac{(b-2)^{2}\left(s_{1}-s_{2}\right)}{9(b-1)}-\frac{1}{2} s_{2}^{2}\right\}
\end{array}\right.
$$

Liao (2008) supposes the market outcome is endogenous to the firms and derives each firm's quality best reply case by case, given the other firm's quality. She

3 Note that Liao (2008) assumes that $\bar{\theta}-\underline{\theta}=1$ or the consumer density is $1 /(\bar{\theta}-\underline{\theta})=1$.

Because this assumption is relaxed in our paper, the consumer density is $1 /(b-1)$. 
compares equilibrium firms' payoffs across regions to identify the 'global' quality equilibrium. She finds that if $b \in(2,4.7125)$, the unique 'global' equilibrium is a market covered with a corner solution by only two firms (Case II).

\subsection{A Country with an arbitrary size}

Lemma 1: When $b \in(2,4.7125)$, a market with a size of $\Psi$ is always covered with a corner solution by only two firms whatever the market size is. In addition, the optimal price and quality of firm $i$ are $\Psi p_{i}^{c}$ and $\Psi s_{i}^{c}$ where $p_{i}^{c}$ and $s_{i}^{c}$ are respectively the optimal price and quality of the firm with the same rank in the Unitary Country.

Proof: We prove Lemma 1 in two steps:

Step 1: We consider a case of 2 firms and follow Liao (2008) to derive problems faced by these firms in each market configuration. Then, we equivalently transform the problems in each region into the ones presented by Liao (2008) by reducing the market size parameter from these problems. As a result, the quality equilibrium in the market will not be characterized by the market size except the impact of market size is on price and quality levels.

Step 2: Then, we prove that other firms can not enter the market.

Now, suppose that only two firms operate in the market. By following Wauthy (1996) and Liao (2008), it is easy to show that the optimal prices (expressed in functions of qualities) are the same as in Liao (2008). In addition, the number of possible market configurations derived from the price selection stage are independent of the market size. Thus, there are three possible market configurations at the price selection stage: uncovered market (Case I), covered market with a corner solution (Case II), and covered market with an interior solution (Case III). ${ }^{4}$

\section{Case I: An uncovered market}

We follow Liao (2008) in the price selection stage, and so the problems faced by firm1 and firm 2 are

4 Pre-empted market is not possible as $b \in(2,4.7125)$. 


$$
\left\{\begin{array}{l}
\text { Firm 1: } \max _{s_{1}} \Pi_{1}^{* * \Psi}=\max _{s_{1}}\left\{\Psi \frac{4 b^{2} s_{1}^{2}\left(s_{1}-s_{2}\right)}{(b-1)\left(4 s_{1}-s_{2}\right)^{2}}-\frac{1}{2} s_{1}^{2}\right\} \\
\text { Firm 2: } \max _{s_{2}} \Pi_{2}^{* * \Psi}=\max _{s_{2}}\left\{\Psi \frac{b^{2} s_{1} s_{2}\left(s_{1}-s_{2}\right)}{(b-1)\left(4 s_{1}-s_{2}\right)^{2}}-\frac{1}{2} s_{2}^{2}\right\}
\end{array}\right.
$$

Now, we let $s_{1}=\Psi q_{1}$ and $s_{2}=\Psi q_{2}$ and then substitute them in (7). Because $\Psi$ is a constant, both firms can equivalently determine the optimal value of $q_{i}$ instead of the optimal value of $s_{i}$. As a result, the problems faced by the two firms now become:

$$
\left\{\begin{array}{c}
\text { Firm 1: } \max _{s_{1}} \Pi_{1}^{* * \Psi}=\max _{\Psi q_{1}}\left\{\Psi \frac{4 b^{2} \Psi^{2} q_{1}^{2}\left(\Psi q_{1}-\Psi q_{2}\right)}{(b-1)\left(4 \Psi q_{1}-\Psi q_{2}\right)^{2}}-\frac{1}{2} \Psi^{2} q_{1}^{2}\right\} \\
\text { Firm 2: } \max _{s_{2}} \Pi_{2}^{* * \Psi}=\max _{\Psi q_{2}}\left\{\Psi \frac{b^{2} \Psi q_{1} \Psi q_{2}\left(\Psi q_{1}-\Psi q_{2}\right)}{(b-1)\left(4 \Psi q_{1}-\Psi q_{2}\right)^{2}}-\frac{1}{2} \Psi^{2} q_{2}^{2}\right\}
\end{array}\right.
$$

Bringing $\Psi^{2}$ out of maximization notations in (8), we have

$$
\left\{\begin{array}{l}
\text { Firm 1: } \max _{s_{1}} \Pi_{1}^{* * \Psi}=\Psi^{2} \max _{q_{1}}\left\{\frac{4 b^{2} q_{1}^{2}\left(q_{1}-q_{2}\right)}{(b-1)\left(4 q_{1}-q_{2}\right)^{2}}-\frac{1}{2} q_{1}^{2}\right\} \\
\text { Firm 2: } \max _{s_{2}} \Pi_{2}^{* * \Psi}=\Psi^{2} \max _{q_{2}}\left\{\frac{b^{2} q_{1} q_{2}\left(q_{1}-q_{2}\right)}{(b-1)\left(4 q_{1}-q_{2}\right)^{2}}-\frac{1}{2} q_{2}^{2}\right\}
\end{array}\right.
$$

Note that since $\Psi^{2}$ is also a constant. The problems in (9) are exactly the same as the ones presented by Liao (2008) in this uncovered market case (as in (3)). This means that the optimal value of $q_{i}(\mathrm{i}=1,2)$ is defined by $q_{i}^{* *}=s_{i}^{* *}$ where $s_{i}^{* *}$ is the optimal product quality of firm $i$ in the market with a size of 1 (Case I of Liao (2008)). Thus, in the market with a size of $\Psi$, the optimal quality decided upon by firm $i$, denoted by $s_{i}^{* * \Psi}$, is $\Psi s_{i}^{* *}$. Based on the problems in (9), the profit of firm $i$ $(\mathrm{i}=1,2)$ at equilibrium is directly proportional to $\Psi^{2}$. It is easy to show that $\Pi_{i}^{* * \Psi}=\Psi^{2} \pi_{i}^{* *}$. Note that $\pi_{i}^{* *}$ is the profit of firm $i$ in Case I of Liao (2008).

\section{Case II: A market covered with a corner solution}

We follow Liao (2008) in the selection stage, and so the problems faced by firm 1 and firm 2 are 


$$
\left\{\begin{array}{l}
\text { Firm 1: } \max _{s_{1}} \Pi_{1}^{c^{\Psi}}=\max _{s_{1}}\left\{\Psi \frac{\left[b s_{1}-(b-1) s_{2}\right]^{2}}{4(b-1)\left(s_{1}-s_{2}\right)}-\frac{1}{2} s_{1}^{2}\right\} \\
\text { Firm 2: } \max _{s_{2}} \Pi_{2}^{c^{\Psi}}=\max _{s_{2}}\left\{\Psi \frac{s_{2}\left[(b-2) s_{1}-(b-1) s_{2}\right]}{2(b-1)\left(s_{1}-s_{2}\right)}-\frac{1}{2} s_{2}^{2}\right\}
\end{array}\right.
$$

In addition, the optimal prices given in functions of qualities are:

$$
\left\{\begin{array}{c}
p_{1}^{c \Psi}=\left[s_{2}+b\left(s_{1}-s_{2}\right)\right] / 2 \\
p_{2}^{c \Psi}=s_{2}
\end{array}\right.
$$

Similarly, we also let $s_{1}=\Psi q_{1}$ and $s_{2}=\Psi q_{2}$ and replace them into (10) and then bring $\Psi^{2}$ out of maximization notations to obtain the following problems:

$$
\left\{\begin{array}{l}
\text { Firm 1: } \max _{s_{1}} \Pi_{1}^{c \Psi}=\Psi^{2} \max _{q_{1}}\left\{\frac{\left[b q_{1}-(b-1) q_{2}\right]^{2}}{4(b-1)\left(q_{1}-q_{2}\right)}-\frac{1}{2} q_{1}^{2}\right\} \\
\text { Firm 2: } \max _{s_{2}} \Pi_{2}^{c \Psi}=\Psi^{2} \max _{q_{2}}\left\{\frac{q_{2}\left[(b-2) q_{1}-(b-1) q_{2}\right]}{2(b-1)\left(q_{1}-q_{2}\right)}-\frac{1}{2} q_{2}^{2}\right\}
\end{array}\right.
$$

Problems in (12) are the same as the ones in (4). Thus, we find $q_{i}^{c}=s_{i}^{c}$ or the optimal quality of firm $i$ is $s_{i}^{c \Psi}=\Psi s_{i}^{c}$ where $s_{i}^{c}$ is the optimal quality of firm $i$ when the market size is 1 (Case II of Liao (2008)). Note that we denote $q_{i}^{c \Psi}$ to be the optimal quality of firm $i$ when the market size is $\Psi$ in the region of market covered with a corner solution.

From (11), the optimal prices can be expressed as follows:

$$
\left\{\begin{array}{c}
p_{1}^{c \Psi}=\left[s_{2}^{c \Psi}+b\left(s_{1}^{c \Psi}-s_{2}^{c \Psi}\right)\right] / 2 \\
p_{2}^{c \Psi}=s_{2}^{c \Psi}
\end{array}\right.
$$

Substituting the optimal quality $s_{i}^{c \Psi}=\Psi s_{i}^{c}$ in (13), we obtain the optimal price $p_{i}^{c \Psi}=\Psi p_{i}^{c}$ where $p_{i}^{c}$ is the optimal price of firm $i$ in Case II of Liao (2008). In addition, we can get firms' profit functions in this market region: $\Pi_{i}^{c \Psi}=\Psi^{2} \pi_{i}^{c}(\mathrm{i}=1,2)$. Note that $\pi_{i}^{c}$ is the profit of firm $i$ in Case II of Liao (2008).

Thus, the optimal price and quality of firm $i$ in this region are:

$$
\left\{\begin{array}{l}
p_{i}^{c \Psi}=\Psi p_{i}^{c} \\
s_{i}^{c \Psi}=\Psi s_{i}^{c}
\end{array}\right.
$$




\section{Case III: A market covered with an interior solution}

We also follow Liao (2008) in the price competition stage, and so the problems faced by firm 1 and firm 2 are:

$$
\left\{\begin{array}{l}
\text { Firm 1: } \max _{s_{1}} \Pi_{1}^{* \Psi}=\max _{s_{1}}\left\{\Psi \frac{(2 b-1)^{2}\left(s_{1}-s_{2}\right)}{9(b-1)}-\frac{1}{2} s_{1}^{2}\right\} \\
\text { Firm 2: } \max _{s_{2}} \Pi_{2}^{* \Psi}=\max _{s_{2}}\left\{\Psi \frac{(b-2)^{2}\left(s_{1}-s_{2}\right)}{9(b-1)} \frac{1}{2} s_{2}^{2}\right\}
\end{array}\right.
$$

Similarly, we also let $s_{1}=\Psi q_{1}$ and $s_{2}=\Psi q_{2}$ and replace them into (15) to arrive at the following problems:

$$
\left\{\begin{array}{l}
\text { Firm 1: } \max _{s_{1}} \Pi_{1}^{* \Psi}=\Psi^{2} \max _{q_{1}}\left\{\frac{(2 b-1)^{2}\left(q_{1}-q_{2}\right)}{9(b-1)}-\frac{1}{2} q_{1}^{2}\right\} \\
\text { Firm 2: } \max _{s_{2}} \Pi_{2}^{* \Psi}=\Psi^{2} \max _{q_{2}}\left\{\frac{(b-2)^{2}\left(q_{1}-q_{2}\right)}{9(b-1)}-\frac{1}{2} q_{2}^{2}\right\}
\end{array}\right.
$$

Problems in (16) are, one-to-one, identical as in (6). Thus, $q_{i}^{*}=s_{i}^{*}$ where $s_{i}^{*}$ is the is the optimal quality of firm $i$ when the market size is 1 (Case III of Liao (2008)). Thus, the optimal product quality of firm $i$ is $s_{i}^{* \Psi}=\Psi s_{i}^{*}$ where $s_{i}^{*}$ is the optimal quality of firm $i$ in Case III of Liao (2008). The profit of firm $i$ is $\Pi_{i}^{* \Psi}=\Psi^{2} \pi_{i}^{*}$. Note that $\pi_{i}^{*}$ is the profit of firm $i$ in Case II of Liao (2008).

We note that the problems faced by both firms in each region are exactly the same as the ones in the corresponding region in Liao (2008) and profits of both firms are increased by a factor of $\Psi^{2}$. Because $\Psi^{2}$ is a constant and $b \in(2,4.7125)$, we can conclude the 'global' equilibrium will be the same as that in Liao (2008). Put differently, the market with a size of $\Psi$ (with only two firms) is also covered with a corner solution.

Because we consider a model with only two firms, we should ask if other entrants can have a positive market share. We note that firm 2 is the one to determine the market is uncovered or covered in the case with two firms as discussed in previous 
papers. Intuitionally, more entry implies more competition or firm 2 will make less profit if it allows the market uncovered. Thus, it will cover the market. ${ }^{5}$

In addition, Liao (2008) shows that the market covered with a corner solution is endogenously determined. When a market is covered, other firms can not enter the market. In other words, only two firms with positive market shares coexist at equilibrium in the country with a market size of $\Psi$. Lemma 1 has been proven.

\subsection{Two countries: Autarkic and trading cases}

Proposition 1: The trade between Home and Foreign increases all good qualities. In addition, it makes goods become more costly to produce as a consequence of the quality improvement, and the trade does not increase variety of goods.

Proof: When Home and Foreign close their doors, the market sizes of Home and Foreign are $\mathrm{T}$ and $\mathrm{U}$, respectively. If Home and Foreign trade each other, a region will be formed and firms will operate in a larger market with a size of $\mathrm{T}+\mathrm{U}$. We note that the regional market characteristics will be identical to those of the market presented in section 3. From Lemma 1, it is straightforward to derive the optimal quality of firm $i$ : $T s_{i}^{c}$ in Home, $U s_{i}^{c}$ in Foreign, and $(T+U) s_{i}^{c}$ in the region (that is, the case in which Home and Foreign trade with each other). In addition, the trade between Home and Foreign does not increase good variety as only two firms coexist at equilibrium.

Now, we prove that the trade makes goods more costly to produce as a consequence of quality improvement. We call $D_{i}^{\Psi}$ the demand for firm $i$ goods in a market with a consumer size $\Psi$. Thus, $D_{i}^{1}$ is the good demand of firm $i$ in a market with a consumer size of 1 (as in Liao, 2008).

In Home without trade, the market size is T. From Lemma 1 and (14), the optimal price and quality decided upon by firm $i$ are $T p_{i}^{c}$ and $T s_{i}^{c}$. Following Wauthy (1996) and Liao (2008), the demands of the two firms are:

$$
\left\{\begin{array}{l}
D_{1}^{T}=\frac{T}{b-1}\left[b-\frac{T p_{1}^{c}-T p_{2}^{c}}{T s_{1}^{c}-T s_{2}^{c}}\right]=\frac{T}{b-1}\left[b-\frac{p_{1}^{c}-p_{2}^{c}}{s_{1}^{c}-s_{2}^{c}}\right]=T D_{1}^{1} \\
D_{2}^{T}=\frac{T}{b-1}\left[\frac{T p_{1}^{c}-T p_{2}^{c}}{T s_{1}^{c}-T s_{2}^{c}}-1\right]=\frac{T}{b-1}\left[\frac{p_{1}^{c}-p_{2}^{c}}{s_{1}^{c}-s_{2}^{c}}-1\right]=T D_{2}^{1}
\end{array}\right.
$$

$5 \quad$ Note that firm 2 is the one that decides to cover or uncover the market. If firm 2 uncovers the market, other firms may enter. For firm 2, the set of strategies to uncover the market is strictly dominated by the one to cover the market when $b \in(2,4.7125)$. Put differently, the market is always covered by firm 2 if $b \in(2,4.7125)$. Detailed proof is provided upon request. 
where the demands of both firms in the Unitary Country (with a market size of 1 or in Liao (2008)) are as follows:

$$
\left\{\begin{array}{l}
D_{1}^{1}=\frac{1}{b-1}\left[b-\frac{p_{1}^{c}-p_{2}^{c}}{s_{1}^{c}-s_{2}^{c}}\right] \\
D_{2}^{1}=\frac{1}{b-1}\left[\frac{p_{1}^{c}-p_{2}^{c}}{s_{1}^{c}-s_{2}^{c}}-1\right]
\end{array}\right.
$$

By dividing the total cost of firm $i,\left(T s_{i}^{c}\right)^{2} / 2$, by its good demand, we have:

$$
A C_{i}^{T}=\frac{\left[\left(T s_{i}^{c}\right)^{2} / 2\right]}{D_{i}^{T}}=\frac{\left[\left(T s_{i}^{c}\right)^{2} / 2\right]}{T D_{i}^{1}}=T \frac{\left(s_{i}^{c}\right)^{2}}{2 D_{i}^{1}}=(T) A C_{i}^{1} \quad i=1,
$$

Where $A C_{i}^{T}(i=1,2)$ is the average cost of firm $i$ in Home and $A C_{i}^{1}=\frac{\left(s_{i}^{c}\right)^{2}}{2 D_{i}^{1}}$ is the average cost of the firm with the same quality rank in the Unitary Country (the market size is 1 or in Liao (2008)).

Similarly, we can derive the average cost of firmi in Foreign without trade:

$$
A C_{i}^{U}=(U) A C_{i}^{1}
$$

As the regional market (Home and Foreign in trade with each other) has a size of $\mathrm{T}$ $+\mathrm{U}$, the average cost of firm $i$ is:

$$
A C_{i}^{T+U}=(T+U) A C_{i}^{1}
$$

By comparing the average costs in (19), (20), and (21), we find that the average costs of both firms increase when countries trade with each other. Proposition 1 is proven.

\subsection{Numerical analysis}

For numerical analysis, we normalize the size of Home to 1 and allow the size of Foreign to change. Thus, the size of Region (Home and Foreign in trade) is U+1. Using Maple Software (Version 15.0) with $b=4$, we obtain values of optimal qualities, prices, and average costs of goods in Home, Foreign, and the Region. The numerical analysis is presented in the following table. 
Table 1: Qualities, prices, and average cost of goods in home, foreign, and the trading region

\begin{tabular}{|c|c|c|c|c|c|c|c|}
\hline $\begin{array}{l}\text { Size of Home (Normalized) }(T=1) \\
\text { Foreign size ( } U=1,2,3 \ldots 7)\end{array}$ & $1(*)$ & 2 & 3 & 4 & 5 & 6 & 7 \\
\hline$s_{1}^{c T}, s_{1}^{c U}$ & 1.329 & 2.658 & 3.987 & 5.316 & 6.645 & 7.974 & 9.303 \\
\hline$s_{2}^{c T}, s_{2}^{c U}$ & 0.248 & 0.496 & 0.744 & 0.992 & 1.240 & 1.488 & 1.736 \\
\hline$p_{1}^{c T}, p_{1}^{c U}$ & 2.286 & 4.572 & 6.857 & 9.143 & 11.429 & 13.715 & 16.001 \\
\hline$p_{2}^{c T}, p_{2}^{c U}$ & 0.248 & 0.496 & 0.744 & 0.992 & 1.240 & 1.488 & 1.736 \\
\hline$A C_{1}^{c T}, A C_{1}^{c U}$ & 1.253 & 2.505 & 3.758 & 5.011 & 6.263 & 7.516 & 8.769 \\
\hline$A C_{2}^{c T}, A C_{2}^{c U}$ & 0.104 & 0.209 & 0.313 & 0.417 & 0.521 & 0.626 & 0.730 \\
\hline $\begin{array}{l}\text { Size of Region } \\
(\mathrm{U}+1=2,3,4 \ldots 8)\end{array}$ & 2 & 3 & 4 & 5 & 6 & 7 & 8 \\
\hline$S_{1}^{c(T+U)}$ & 2.658 & 3.987 & 5.316 & 6.645 & 7.974 & 9.303 & 10.632 \\
\hline$s_{2}^{c(T+U)}$ & 0.496 & 0.744 & 0.992 & 1.240 & 1.488 & 1.736 & 1.984 \\
\hline$p_{1}^{c(T+U)}$ & 4.572 & 6.857 & 9.143 & 11.429 & 13.715 & 16.001 & 18.286 \\
\hline$p_{2}^{c(T+U)}$ & 0.496 & 0.744 & 0.992 & 1.240 & 1.488 & 1.736 & 1.984 \\
\hline$A C_{1}^{c(T+U)}$ & 2.505 & 3.758 & 5.011 & 6.263 & 7.516 & 8.769 & 10.022 \\
\hline$A C_{2}^{c(T+U)}$ & 0.209 & 0.313 & 0.417 & 0.521 & 0.626 & 0.730 & 0.834 \\
\hline
\end{tabular}

Note: The data in this column marked $(*)$ is of both countries, Home and Foreign.

As shown in Table 1, both quality levels as well as average costs of goods increase when Home and Foreign trade with each other. Thus, the numeric analysis totally supports the findings derived from the theoretical part of this paper.

\section{Conclusion}

This paper has examined the impact of VIIT on firms' behaviors regarding price and quality choices. Extending the model of Liao (2008), we find that firms will select higher levels of quality for their goods as international trade expands the 
market size. As a result, goods become more costly to produce. In addition, we have proven that trade does not increase good variety. Thus, we argue that New Trade Theory might not explain the trade of quality differentiated goods.

We employ a specific assumption that limited the difference in consumer preference so that only two firms can participate in the game, but we believe our result may be widely applicable, even in cases with a greater number of firms.

\section{REFERENCES}

Beloqui, L. \& Usategui, J. M. (2005). Vertical differentiation and entry deterrence: A reconsideration. DFAEII Working Paper 2005-06.

Fontangé, L., Freudenberg, M., \& Gaulier, G. (2006). A systematic decomposition of world trade into horizontal and vertical IIT. Review of World Economics, $142,459-475$.

Greenaway, D., Hine, R. C., \& Milner, C. R. (1994). Country-specific factors and the pattern of horizontal and vertical intra-industry trade in the UK. Review of World Economics, 130, 77-100.

Gruber, W., Mehta D., \& Vernon, R. (1974). The R\&D factor in international trade and international investment of United States industries. Journal of Political Economy, 75, 20-37.

Krugman, P. (1979). Increasing returns, monopolistic competition, and international trade. Journal of International Economics, 9, 469-479.

Lancaster, K. (1980). Intra-industry trade under perfect monopolistic competition. Journal of International Economics, 10, 151-75.

Liao, P-C. (2008). A note on market coverage in vertical differentiation models with fixed costs. Bulletin of Economic Research,60(1), 0307-3378.

Motta, M. (1993). Endogenous quality choice: price vs. quantity competition. Journal of Industrial Economics,41, 113-132.

Mussa, M. \& Sherwin, R. (1978). Monopoly and product quality. Journal of Economic Theory, 18, 301-317.

Niem, L. D. \& Kim, T. G. (2014). Economic development, vertical intra-industry trade and gains from trade. Modern Economy, 5, 1-10.

Shaked, A., \& Sutton, J. (1982). Relaxing price competition through product differentiation. Review of Economic Studies, 49(1), 3-13.

Sutton, J. (1986). Vertical product differentiation: some basic themes. American Economic Review: Papers and Proceedings, 76, 393-398.

Tirole, J. (1988). The Theory of Industrial Organization, Cambridge, MA: MIT Press.

Wauthy, X. (1996). Quality choice in models of vertical differentiation. Journal of Industrial Economics, 3, 345-353. 